\title{
Feedback in Academic Writing: Using Feedback to Feed-Forward
}

\author{
Debra Jones \\ Tokyo Woman's Christian University, Japan
}

\begin{abstract}
Feedback is a key element of both teaching and learning in academic writing. Students generally take note of feedback on the first draft of an essay, as they are required to rewrite it and are motivated to achieve a good grade. However, feedback on final drafts is often ignored or forgotten before the next essay. This can be frustrating for teachers, as well as a missed opportunity for students to learn lessons from the final draft and take these forward to the next essay. This paper describes an attempt to implement the concept of "feed-forward" by encouraging students to engage actively with final draft feedback and be more proactive in the feedback process through feedback dialogues with the teacher. Current literature on feedback and evaluation is reviewed, followed by an explanation of the methods adopted. Results are then analyzed and, although tentative at this stage, are judged to be positive.
\end{abstract}

This paper describes an action research study undertaken at a Japanese university to facilitate active student engagement in the feedback process as a way of developing student writing skills and increasing learner autonomy. The classes followed the process writing method of drafting, revising, and rewriting with feedback given at each stage. Students were generally motivated to read and respond to feedback at the drafting stages, knowing that they would have the opportunity to rewrite and improve the essay. However, when the final essay was returned, there was a tendency for students to see it as a finished product. Any feedback given on the final draft was either not read or not acted upon.

This study was an attempt to encourage students to read and respond to final draft teacher feedback and carry forward ideas for improvement to the next essay, hence the term feedforward. This paper does not claim to have invented this term, defined by Duncan (2007) as applying old feedback to a new task (see also Duncan, Prowse, Wakeman, \& Harrison, 2004; Higgins, Hartley, \& Skelton, 2001; Murtagh \& Baker, 2009; Rae \& Cochrane, 2008). This study represents a practical attempt to implement a feed-forward approach in the classroom. The next section will review current literature on feedback and evaluation as it relates to academic writing. The aims and methods of the study will then be described, followed by a discussion of the results and future research possibilities. 


\section{Literature Review}

\section{Process Writing}

The emergence of process writing in the field of ESL in the early 1980s has been well documented. As its name suggests, it is characterized by a shift in focus from the final product to the process of achieving the final product (Matsuda, 2003; Myers, 1997; Tribble, 1996). The process approach has many advantages, including developing student autonomy and evaluative skills by fostering students' sense of ownership and responsibility for revising their own work (Wakabayashi, 2008). In addition, the emphasis of process over product has prompted a change in attitudes towards evaluation and assessment (Gibbs \& Simpson, 20042005; Wada, 2006).

\section{Summative Versus Formative Evaluation}

Traditionally, assessment has been seen as a judgment on the final product, or summative evaluation, as opposed to a constructive contribution to a work in progress, or formative evaluation (see Boston, 2002; Collins, 2004; Sadler, 1989). According to Gibbs \& Simpson (2004-2005), if feedback is to support learning, students must have the opportunity to act on it, while Wiggins (2004) maintains that feedback is more beneficial if given during rather than after performance. This supports the research into assessment for learning conducted by Black and Wiliam (1998), which further suggests that feedback is more effective when it gives guidance on strengths and weaknesses without a grade being assigned. Process writing lends itself to this approach since feedback on early drafts does not usually include a grade and students have the chance to act on feedback received to improve their essay and develop their writing skills (Carless, 2006; Ferris, 2003). Of course, formative feedback can be written on a final draft when a grade is assigned (Collins, 2004), but students are not inclined to read it, as they do not necessarily see how comments on one assignment might help them with an assignment on a different topic (Carless, 2006; Duncan et al., 2004). Once the final product has been submitted and graded, it is seen as the end of the process rather than as another step in a much longer process.

\section{Teacher Feedback}

This trend towards using feedback and assessment for learning has produced an increasing body of research, although more is needed (Carless, 2006; Mutch, 2003), particularly in an EFL context. Given the amount of time and effort expended on writing feedback, teachers want their feedback to be effective (Duncan, 2007; Ferris, 2003). Research has focused on what kind of feedback to give (form or content), especially in EFL writing (Myers, 1997; Newfields, 2003; Tribble, 1996; Wada, 2006), and also on ways of giving feedback (Falout, 2008). A number of studies have examined student responses to teacher feedback with some supporting the view that students take very little notice of feedback and are only concerned about the grade (Chanock, 2000; Ecclestone, 1998; Hounsell, 1987). Other findings indicate that students do value feedback (Duncan, 2007; Taras, 2003; Weaver, 2006); moreover, they expect it and feel they deserve it (Higgins, Hartley \& Skelton, 2002). However, most research suggests that feedback, even when valued, is often not as helpful as students would like or as teachers would like to think (Carless, 2006; Gibbs \& Simpson, 2004-2005; Hounsell, McCune, Hounsell \& Litjens, 2008). Feedback has been criticized for being unclear or vague and for not providing advice or guidance (Chanock, 2000; Murtagh \& Baker, 2009; Weaver, 2006). There are indications that teachers and students perceive the effectiveness of the feedback process very differently (Carless, 2006; Higgins et al., 2001; Mutch, 2003), all of which suggests the need to find new ways of giving written feedback in the context of a more formative approach to evaluation. 


\section{Feedback Dialogues}

The literature has also emphasized that feedback is more effective when it allows students to take some responsibility for their own learning (Sadler, 1989; Weaver, 2006). One of the goals of feedback should be to develop autonomous learners (Murtagh \& Baker, 2009) able to "selfmanage" learning, and one role of teachers is to encourage them to do this (Rae \& Cochrane, 2008). The process approach offers such opportunities, but requires a move away from the idea of feedback as "a linear transfer of information" from teacher to student (Higgins et al., 2001, p. 271) towards more of a dialogue (Carless, 2006; Hyland \& Hyland, 2006). This allows for an ongoing process of negotiation in which students are actively engaged in order to reduce the possibility of confusion and misunderstanding (Taras, 2003). In addition, the idea of feedback as a dialogue requires teachers to consider what feedback students want and how they respond to it (Carless, 2006; Mutch, 2003), potentially improving the effectiveness of teacher feedback. The dialogue concept is also supported by research into the interpersonal aspects of teachers' written feedback by Hyland \& Hyland (2006), which emphasizes feedback as an ongoing process focusing on text, learning context, and the needs of individual students rather than simply a response to each text in isolation.

\section{Aims}

This study represents an attempt to establish a feedback dialogue approach with the following aims:

1. To facilitate active student engagement in the feedback process by encouraging students to reflect and act on final draft teacher feedback by feeding-forward to the next assignment. Despite references to the feed-forward idea in the literature, there have been few attempts to put it into practice (see Duncan, 2007; Duncan et al, 2004).

2. To increase learner autonomy by giving students the opportunity to set goals and request feedback on specific aspects of their essays.

3. To improve the effectiveness of teacher feedback in responding to the concerns of students.

\section{Methodology}

The project was carried out over a two-year period with second-year and third-year English majors at a Japanese university.

\section{Teaching Context}

Students are required to produce five or six essays during the year, with each assignment involving at least a first and final draft. After the first draft, students receive a combination of peer and teacher feedback as well as engage in self-evaluation activities in the form of checklists. Teacher feedback is written on a First Draft Evaluation form (see Appendix A). Students are given detailed feedback on organizational aspects of the essay and on content. The criteria depend on the focus of the essay and are different for second-year and third-year students to reflect the different aims of these classes. The scores from 1 to 5 give students an indication of the strengths and weaknesses of the essay and do not represent a grade. The comment box provides an opportunity for comments on additional areas such as writing style, and for advice and guidance on how to improve the essay. Grammatical or vocabulary issues are highlighted on the essay itself. On the return of the final draft, students are given feedback on a Final Essay Evaluation sheet (see Appendix B). The 1-5 scale is a way of highlighting the strengths and weaknesses of the essay, but the letter grade is a holistic assessment based on the 
overall impression of the essay rather than the sum of its parts. This feedback combines a summative evaluation of the essay and a formative assessment, including advice on areas for improvement in the comments section.

\section{This Study}

The study introduced an additional stage in the feedback process with a "feed-forward" form (see Appendix C). When the final draft of Essay 1 was returned with a grade and feedback, students were asked to read the feedback and identify two goals for the next essay. They wrote the goals on the form and the forms were collected. On submission of the first draft of Essay 2, students were asked to review the goals they had set, decide if they had made any progress towards achieving their aims, and write their responses on the form. They also had the opportunity at this point to write questions about their essays. The feed-forward forms were then submitted with the first drafts. On the return of the first draft of Essay 2, students received feedback on a first draft evaluation form as well as responses to their questions on the feedforward form. They began revisions to their essays in class so they could ask questions to clarify the feedback or ask for advice on how to implement the improvements suggested. When the students submitted the final draft of Essay 2, they wrote two questions or identified two areas they specifically wanted feedback about on the feed-forward form and submitted it with their essay. Their questions could either relate to their first draft goals or to a different issue. On return of the final draft, students received comments on a final draft feedback form and also a response to the questions on the feed-forward form. At this point, the process began again; students were asked to read the feedback in class and identify two goals for Essay 3 . In this way, a more cyclical process of feedback was established (Hounsell et al., 2008) which acknowledged the relationship between each essay and the ongoing development of each student.

\section{Results and Discussion}

This method has been adopted for two academic years, or four semesters. However, the data collected and analysed was based on only one semester, so the sample is small and the results not conclusive at this stage. The results will be discussed in terms of the aims stated above.

\section{Encouraging Students to Reflect on Final Draft Feedback and Feed-Forward}

In respect of the first aim, the study was successful. Students were given time to read the feedback in class. They had to think about the feedback and respond by identifying future goals based on it. The feed-forward forms established a concrete connection between each essay assignment for students. At the end of the year, a questionnaire was carried out amongst students who had participated in the study (see Appendix D). The questionnaires were anonymous and students were told that any responses, both positive and negative, would be useful for research purposes.

For Question 1, over 90\% circled a combination of the first 4 answers:

1. I enjoyed it / it was helpful.

2. I didn't like doing it but it was helpful.

3. It made me think more about how to improve my writing.

4. It made me read the feedback on my essay more carefully.

Of 42 students who completed the survey, three responded that it took too much time and one did not understand why she was doing it. 
The responses to Questions 2-5 are as follows:

2. Was it useful to ask questions and get answers from me on the form?
a. Yes - 39
No - 0
Not Sure - 3

3. Did you like setting your own goals for your next essay?
a. Yes -31
No -3
Not Sure - 8

4. Did the Feed-forward forms help you understand your mistakes better?
a. Yes -42
No - 0
Not Sure - 0

5. Do you think the Feed-forward form helped you improve your writing?
a. Yes -40
No - 0
Not Sure - 2

In addition, there was an opportunity for students to write comments about the feedback they received. Only a small number of students wrote responses, but all comments were positive.

The sample was small and these students are, for the most part, well motivated and not inclined to respond negatively; however, their responses are certainly encouraging. The comments written on the feed-forward forms were detailed and thoughtful; they suggest students did reflect carefully on the feedback and how to use it and did not simply do it just to get it done (see Appendix E). From the teacher's perspective, students in both classes did show improvement from the first draft to the final draft and over the course of the year, but it is not possible to say if this is directly connected to the feed-forward forms. Further research would be needed to assess the extent to which improvements related to the goals set on the feedforward forms. In addition, the form could be modified to ask students to specify what improvements they had made rather than just asking them if they felt they had improved. This would provide useful data on how students use feedback, which is an area in need of further research.

\section{Increasing Students' Autonomy and Sense of Responsibility for Their Own Learning}

The second aim was achieved by asking students, on submission of the final draft, to be proactive and request feedback on points of concern rather than rely solely on the teacher's judgment. In addition, students were asked to set their own goals. The responses to Question 3, about goal setting, were not as overwhelmingly positive as the responses to Questions 2, 4, and 5, suggesting some reluctance or uncertainty by students. This may indicate the need for more support and scaffolding to develop students' ability to evaluate, edit, and revise their work based on their own decisions. One way to do this would be to use checklists of possible goals for students to choose from until they become confident enough to set their own. Alternatively, students could summarize the feedback they receive, discuss it with their peers and set goals for each other as a step towards setting goals for themselves.

It is possible students felt constrained by the design of the form, which asked them to set their own goals in response to feedback received. They may not have understood the feedback and so felt unable to set goals based on it, or else they wanted to set goals that were important for them, but were not based on the feedback, suggesting a possible gap between the priorities of the teacher and the concerns of the students. This raises the question of the relevance of teacher feedback, which leads to the third aim. 


\section{Improving Feedback Effectiveness by Direct Response to Student Concerns}

Possibly one of the most significant benefits of this study was that, through dialogue, the teacher could provide more focused, targeted feedback that directly responded to student concerns. It can be speculated that students were more motivated to read and act on feedback that responded to their questions, thereby improving the effectiveness of teacher feedback. More research needs to be done to establish if this is the case.

Some analysis was done on the kind of questions students asked and an attempt was made to compare student priorities with those of the teacher (see Appendix F). The results are tentative and somewhat predictable. Briefly, they suggest that students focus more on grammatical and lexical problems than the teacher feedback does. In contrast, the teacher feedback emphasizes content, whereas students see this as less of a priority and are less likely to spontaneously ask for feedback on this point. The feed-forward forms provide a useful source of data for further research in this area.

\section{Additional Benefits of the Study}

1. The feed-forward form provided a record of progress throughout the semester for both student and teacher.

2. Questions asked by the students on the feed-forward forms highlighted areas of difficulty which could then be reviewed in class, thus providing valuable feedback for the teacher on the success of the lessons.

\section{Conclusion}

Overall, the study was successful in terms of its primary aims of (1) encouraging students to make use of final draft feedback and to see each essay as the next step in the process of developing their writing, (2) increasing student autonomy, and (3) improving the effectiveness of feedback by finding out what feedback students want and responding to it. Based on the questionnaire responses and anecdotal evidence, the initial response from students has been positive, but more research is needed on the connection between the feed-forward system and improvements made. As a means of enhancing the effectiveness of the feedback process, the feed-forward system described in this study has much to recommend it in both academic and general writing classes.

\section{Author Note}

Debra Jones, Tokyo Woman's Christian University, Tokyo, Japan.

Correspondence regarding this article should be addressed to Debra Jones. Email: debraj66@gmail.com 


\section{References}

Black, P., \& Wiliam, D. (1998). Inside the black box: Raising standards through classroom assessment. London, England: Kings College.

Boston, C. (2002). The concept of formative assessment. Practical Assessment, Research and Evaluation, 8(9). Retrieved from http://PAREonline.net/getvn.asp? $\mathrm{v}=8 \& \mathrm{n}=9$

Carless, D. (2006). Differing perceptions in the feedback process. Studies in Higher Education, 31(2), 219-233. http://dx.doi.org/10.1080/03075070600572132

Chanock, K. (2000). Comments on essays: Do students understand what tutors write? Teaching in Higher Education, 5(1), 95-105. http://dx.doi.org/10.1080/135625100114984

Collins, J. (2004). Written feedback on student papers. Retrieved from http://departments.knox.edu/facdev/PaperFeedback.html

Duncan, N. (2007). 'Feed-forward': Improving students' use of tutors' comments. Assessment \& Evaluation in Higher Education, 32(3), 271-283. http://dx.doi.org/10.1080/02602930600896498

Duncan, N., Prowse, S., Wakeman, C., \& Harrison, R. (2004). 'Feed-forward': Improving students' use of tutors' comments. Retrieved from http://hdl.handle.net/2436/3778

Ecclestone, K. (1998). 'Just tell me what to do': Barriers to assessment-in-learning in higher education. Paper presented at Scottish Educational Research Association Annual Conference, University of Dundee, September 25-26.

Falout, J. (2008). Emotional scaffolding through editing conferences. The Language Teacher, $32(12), 9-14$.

Ferris, D. (2003). Responding to writing. In B. Kroll (Ed.), Exploring the dynamics of second language writing (pp. 119-140). New York: Cambridge University Press.

Gibbs, G., \& Simpson, C. (2004-2005). Conditions under which assessment supports students' learning. Learning and Teaching in Higher Education, 1, 3-31.

Higgins, R., Hartley, P., \& Skelton, A. (2001). Getting the message across: The problem of communicating assessment feedback. Teaching in Higher Education, 6(2), 269-274. http://dx.doi.org/10.1080/13562510120045230

Higgins, R., Hartley, P., \& Skelton, A. (2002). The conscientious consumer: Reconsidering the role of assessment feedback in student learning. Studies in Higher Education, 27(1), 53 64. http://dx.doi.org/10.1080/03075070120099368

Hounsell, D. (1987). Essay writing and the quality of feedback. In J. T. E. Richardson, M. W. Eysenck, \& D. W. Piper (Eds.), Student learning: Research in education and cognitive psychology. Milton Keynes, England: SRHE/Open University.

Hounsell, D., McCune, V., Hounsell, J., \& Litjens, J. (2008). The quality of guidance and feedback to students. Higher Education Research and Development, 27(1), 55-67. http://dx.doi.org/10.1080/07294360701658765

Hyland, K., \& Hyland, F. (2006). Interpersonal aspects of response: Constructing and interpreting teacher written feedback. K. Hyland \& F. Hyland (Eds.), Feedback in second language writing: Contexts and issues. Cambridge, England: Cambridge University Press.

Matsuda, P. K. (2003). Second language writing in the twentieth century: A situated historical perspective. In B. Kroll (Ed.), Exploring the dynamics of second language writing (pp. 15-34). New York: Cambridge University Press.

Murtagh, L., \& Baker, N. (2009). Feedback to feed forward: Student response to tutors `written comments on assignments. Practitioner Research in Higher Education, 3(1), 20-28.

Mutch, A. (2003). Exploring the practice of feedback to students. Active Learning in Higher Education, 4(1), 24-38. http://dx.doi.org/10.1177/1469787403004001003 
Myers, S. (1997). Teaching writing as a process and teaching sentence level syntax: Reformulation as ESL composition feedback. TESL-EJ, 2(4). Retrieved from http://www.cc.kyoto-su.ac.jp/information/tesl-ej/ej08/a2.html

Newfields, T. (2003). Helping Asian EFL students acquire academic writing skills. Journal of Nanzan Junior College, 30, 99-120.

Rae, A. M., \& Cochrane, D. K. (2008). Listening to students: How to make written assessment feedback useful. Active Learning in Higher Education, 9(3), 217-230. http://dx.doi.org/10.1177/1469787408095847

Sadler, D. R. (1989). Formative assessment and the design of instructional systems. Instructional Science, 18(2), 119-144. http://dx.doi.org/10.1007/BF00117714

Taras, M. (2003). To feedback or not to feedback in student self-assessment. Assessment \& Evaluation in Higher Education, 28(5), 549-565. http://dx.doi.org/10.1080/02602930301678

Tribble, C. (1996). Writing. Oxford, England: Oxford University Press.

Wada, H. (2006). Evaluation criteria for students' academic writing: An action research. Retrieved from http://cicero.u-bunkyo.ac.jp/lib/kiyo/fsell2006/EIBUN185_193.pdf

Wakabayashi, R. (2008). The effect of peer feedback on EFL writing: Focusing on Japanese university students. OnCue Journal, 2(2), 92-110.

Weaver, M. (2006). Do students value feedback? Student perceptions of tutors' written responses. Assessment \& Evaluation in Higher Education, 31(3), 379-394. http://dx.doi.org/10.1080/02602930500353061

Wiggins, G. (2004). Assessment as feedback. Retrieved from http://education.jhu.edu/newhorizons/strategies/topics/Assessment\%20Alternatives/wig gins.htm 
Appendix A

First Draft Evaluation Form

\begin{tabular}{|c|c|c|c|c|c|}
\hline Key Components & \multicolumn{5}{|c|}{ Comment } \\
\hline $\begin{array}{l}\text { Introduction contained } \\
\text { background information; } \\
\text { thesis statement and main } \\
\text { points of the essay were } \\
\text { clearly stated. }\end{array}$ & & & & & \\
\hline $\begin{array}{l}\text { Paragraph topics were clear } \\
\text { and supported the thesis; } \\
\text { supporting sentences gave } \\
\text { details and examples to } \\
\text { support the topic sentence. }\end{array}$ & & & & & \\
\hline $\begin{array}{l}\text { Conclusion restates the thesis, } \\
\text { summarizes the main points } \\
\text { and effectively brings the essay } \\
\text { to a close. }\end{array}$ & & & & & \\
\hline $\begin{array}{l}\text { Essay was appropriate length. } \\
\text { Content was thoughtful. Ideas } \\
\text { were well supported with } \\
\text { evidence and examples from } \\
\text { sources. }\end{array}$ & & & & & \\
\hline Content & 5 & 4 & 3 & 2 & 1 \\
\hline Organisation & 5 & 4 & 3 & 2 & 1 \\
\hline Comments: & & & & & \\
\hline
\end{tabular}

*This form was adapted from feedback forms used in the School of International and Liberal Studies at Waseda University, Tokyo, where the author previously worked. 


\section{Appendix B}

Final Essay Evaluation Form

\section{Name:}

Your essay is graded on three elements: content (what you say), organization (how well you organize your ideas into a 5-paragraph essay structure) and clarity (how clearly you express your ideas in English). The scores in the box helps you understand what was good about your essay and what you need to improve. The final letter grade is awarded for the overall essay, taking into account all the strong and weak points.

$$
5=\text { Excellent } \quad 4=\text { Very good } \quad 3=\operatorname{Good} \quad 2=\text { Needs Improvement } \quad 1=\text { Poor }
$$

$\begin{array}{llllll}\text { Content: } & 5 & 4 & 3 & 2 & 1\end{array}$

(Length was appropriate, content was relevant and ideas were developed with details, explanation and examples from sources)

$\begin{array}{llllll}\text { Organisation: } & 5 & 4 & 3 & 2 & 1\end{array}$

(Essay is organized in a 5-paragraph essay structure with a clear thesis statement; thesis is supported in the body of the essay; conclusion summarizes the essay and brings it to a close effectively)

$\begin{array}{llllll}\text { Clarity: } & 5 & 4 & 3 & 2 & 1\end{array}$

(Vocabulary was appropriate; grammar errors were few and not serious, so meaning was clear and essay was easy to read)

\section{Comments:}




\section{Appendix C \\ Feed-Forward Form}

\section{Return of the Final Draft of Essay 1}

After reading the feedback on your essay, what two things do you want to improve in your next essay? (Be specific - don't just say "organization.")

1.

2 .

\section{Submission of the First Draft of Essay 2}

Look at the two points you said you wanted to improve after completing the first essay. Do you think you have improved in these two areas? If you are not sure, or if you have any questions, write them here.

1.

2 .

My response:

\section{Submission of the Final Draft of Essay 2}

What two aspects of your essay would you like feedback about? If you have any questions you want to ask me about your essay, write them here.

1.

2.

My response:

\section{Return of the Final Draft of Essay 2}

After reading the feedback on your essay, what two things do you want to improve in your next essay? (Be specific - don't just say "organization.")

1.

2.

\section{Submission of the First Draft of Essay 3}

Look at the two points you said you wanted to improve after completing the second essay. Do you think you have improved in these two areas? If you are not sure, or if you have any questions, write them here.

1.

2.

My response: 


\section{Appendix D \\ Questionnaire}

1. How did you feel about the completing the Feed-forward forms? (Circle the answer(s) you agree with - you can circle more than one)

I enjoyed it and it was helpful

I didn't like doing it but it was helpful

It made me think more about how to improve my writing

It made me read the feedback on my essay more carefully

It took too much time

It was boring

I didn't understand the teacher's responses / writing

I didn't understand why I was doing it

2. Was it useful to ask questions and get answers from me on the form?

Yes No Not Sure

3. Did you like setting your own goals for your next essay?

Yes No Not Sure

4. Did the Feed-forward forms help you to understand your mistakes better?

Yes No Not Sure

5. Do you think the Feed-forward form helped you to improve your writing?

Yes No Not Sure

6. Do you have any other comments on the essay feedback you received? 


\section{Appendix E \\ Feed-Forward Form Example}

\section{1/9 Submission of Final Draft of Essay 1}

What aspects of your essay would you like feedback about? Are there any questions you would like to ask about your essay?

1. I want to know how to use conjunctions again.

2. Can I use past tense about movies?

\section{My response:}

1. You can make some of your short sentences into longer sentences by using conjunctions such as 'so' 'and' 'but' (see BP3).

2. We usually use present tense for plot summaries of films and novels but the main thing is to be consistent.

\section{1/16 Return of Final Draft of Essay 1}

After reading the feedback on your essay, what two things do you want to improve in your next essay? (Be specific - don't just say "organization.")

1. Write longer sentences!

2. Use conjunctions effectively!

\section{1/30 Submission of First Draft of Essay 2}

Look at the two points you said you wanted to improve after completing the first essay. Do you think you have improved in these areas? If you're not sure, or if you have any questions, write them here.

1. I tried to write longer sentences and I believe I could.

2. It's difficult to use conjunctions, but I tried hard.

\section{My response:}

1. I think so too! I didn't notice any sentences that were too short.

2. You did much better with conjunctions.

\section{2/14 Submission of Final Draft of Essay 2}

What aspects of your essay would you like feedback about? Are there any questions you would like to ask about your essay?

1. I quoted parts of poem in BP1. How is it?

2. I forgot writing "work consulted". I'm sorry.

\section{My response:}

1. You quoted correctly but the lines you quoted don't really support your point. Other lines would be better.

2. $O K !$

\section{1/11 Return of Final Draft of Essay 2}

After reading the feedback on your essay, what two things do you want to improve in your next essay? (Be specific - don't just say "organization.")

1. I want to choose correct quotations

2. I should write examples which support my idea 


\section{Appendix F \\ Content Analysis of Questions and Comments on Feed-Forward Forms}

Thirty forms were analyzed. Some forms were not included because they were incomplete due to student absence on the day of submission or return of the forms. The forms contained two types of questions: directed, where students had to set goals in response to feedback received, and undirected, where students could ask about any aspect of their essay without reference to teacher feedback. Common categories of feedback were identified, for example, organization, content, quotations and citations, grammar and vocabulary, style, and coherence. Each comment from each form was placed into one of the categories. The results are as follows:

\begin{tabular}{|l|c|c|}
\hline \multicolumn{1}{|c|}{ Categories } & $\begin{array}{c}\text { Responses to } \\
\text { directed questions }\end{array}$ & $\begin{array}{c}\text { Responses to } \\
\text { undirected questions }\end{array}$ \\
\hline Essay structure / Organization & $33.0 \%$ & $30.0 \%$ \\
\hline $\begin{array}{l}\text { Content (including use of examples, details } \\
\text { for support) }\end{array}$ & $24.5 \%$ & $14.5 \%$ \\
\hline Quoting and citing sources & $11.5 \%$ & $14.5 \%$ \\
\hline Grammatical accuracy & $18.0 \%$ & $23.0 \%$ \\
\hline Vocabulary & $5.0 \%$ & $10.0 \%$ \\
\hline Academic style & $3.0 \%$ & $2.0 \%$ \\
\hline Coherence / Logical order & $0.0 \%$ & $3.0 \%$ \\
\hline Other (including spelling / layout) & $4.5 \%$ & $2.0 \%$ \\
\hline
\end{tabular}

*Percentages were rounded up or down to 0.5 or the nearest whole number.

The main areas of discrepancy are in terms of content and grammar and vocabulary. Thirtythree percent of undirected questions refer to grammar and vocabulary compared with $23 \%$ of responses to feedback suggesting that students focus more on grammatical and lexical problems than the teacher feedback does. In contrast, there are more content-based responses to directed questions, suggesting that teacher feedback emphasizes content, whereas students see this as less of a priority and are less likely to spontaneously ask for feedback on this point. 